\title{
Treatment of pulmonary exacerbations in cystic fibrosis
}

\author{
Jayesh M. Bhatt \\ Affiliations: Nottingham Children's Hospital, QMC, Nottingham, UK. \\ Correspondence: J.M. Bhatt, Nottingham Children's Hospital, East Block, QMC, Derby Road, Nottingham, NG7 \\ 2UH, UK. E-mail: jayesh.bhattanuh.nhs.uk \\ ABSTRACT Pulmonary exacerbations have very important consequences in cystic fibrosis (CF), both in \\ terms of current morbidity as well as implications for long term morbidity and mortality. Even though there \\ is no universally agreed definition of pulmonary exacerbation, prompt and aggressive treatment with a \\ multidisciplinary approach is recommended. Maintenance treatments reduce the risk of exacerbations. \\ Antibiotics should be targeted against the common CF bacteria and these can be given orally, although i.v. \\ antibiotics will be required for ongoing symptoms or severe exacerbations. The evidence base for \\ recommendations regarding the optimal regimens, route and frequency of administration of antibiotics, \\ location, and duration of i.v. antibiotic treatment will be discussed. Management of comorbidities, like poor \\ nutrition and diabetes, is critical in improving outcomes.
}

0 @ERSpublications

Pulmonary exacerbations in CF require prompt and aggressive treatment and a multidisciplinary approach is recommended http://ow.ly/mK5df

\section{Introduction}

Cystic fibrosis (CF) is the most common life-limiting autosomal recessively inherited condition in the UK, affecting more than 9300 patients [1]. It is a multisystem disorder but lung disease is the major cause of the significant morbidity and mortality. The natural history of CF lung disease is one of chronic progression with intermittent episodes of acute worsening of symptoms, which are called "pulmonary exacerbations $(\mathrm{PEx})$ ". Pulmonary exacerbations are responsible for much of the morbidity and mortality.

It has been proposed in a recent editorial [2] that exacerbation of various pulmonary conditions should be termed "lung attack" (like "heart attack" for myocardial infarction), with the aim that this term will resonate more with patients and could lead to a systemic approach to management of these conditions by healthcare providers.

A review of the literature on management of pulmonary exacerbations in CF is presented; even though it is a review of international literature, many of the recommendations are based on the author's experience of managing $\mathrm{CF}$ in the UK.

\section{Definitions}

DAKIN et al. [3] suggest that ideally an exacerbation would be defined in terms of an objective chemical, physiological, or histological marker but no such marker has, as yet, been agreed and the definition of a pulmonary exacerbation remains a clinical one. The American Cystic Fibrosis Foundation gives a simple definition in the family handbook as "Exacerbation - Signs and symptoms that show a need for treatment" [4].

There are several (not universally agreed) definitions of pulmonary exacerbations but there is no consensus regarding the diagnostic criteria for pulmonary exacerbations, which are arguably the most important

Received: Oct 252012 | Accepted after revision: Dec 112012

Conflict of interest: None declared.

Provenance: Submitted article, peer reviewed.

Copyright @ERS 2013 
clinical event we deal with in patients with CF. Some studies have classed a physician defined requirement to treat with new antibiotic therapy as a pulmonary exacerbation $[5,6]$. However, there are significant variations in identifying and treating pulmonary exacerbations at individual clinician level, both within the same centre and between centres [3,7]. These variations could be in the clinician's preference for the route of antibiotic administration (i.v., oral, new nebulised) as well as the threshold for starting treatment. The access to inpatient treatment in different countries will also differ. Another approach uses a cluster of symptoms and signs $[8,9]$ that indicate a recent change in clinical parameters or define a minimal criteria (one of the major criteria alone, or two of the minor signs/symptoms present for $\geqslant 5$ days or of significant symptom severity [10]) to define the clinical need for additional treatment with i.v. antibiotics. RABIN et al. [11] examined patient registry data in order to predict the factors that were associated with new treatment. The scoring system developed by RABIN et al. [11] defines separate criteria for different age groups and includes a definition of exacerbations for children $<6$ years-old. This was validated in a recent study which confirmed that the presence of four characteristic signs and symptoms is useful to define pulmonary exacerbations in young children with CF [12].The European Consensus Group's view is that the clinical need for additional treatment, as indicated by a recent change in clinical parameters, provides the best definition of an exacerbation [13]. It defines a pulmonary exacerbation as follows. An exacerbation will be defined as the need for additional antibiotic treatment as indicated by a recent change in at least two of the following: change in sputum volume or colour; increased cough; increased malaise, fatigue or lethargy; anorexia or weight loss; decrease in pulmonary function by $\geqslant 10 \%$ or radiographic changes; increased dyspnoea. These features have been used to define a pulmonary exacerbation in national treatment guidelines [14].

\section{Pulmonary exacerbations and inflammation}

Persistent lower airway infection with inflammation is the major cause of morbidity and mortality in CF and contributes to decline in lung function. Neutrophil driven inflammation is exaggerated, prolonged and may even pre-date infection. Anti-inflammatory therapy, for example with Azithromycin, is well established in the treatment of CF lung disease. During pulmonary exacerbations, there is further aggravation of pulmonary inflammation; however, this is hard to quantify and the systemic host inflammatory response is used as a marker of disease activity. During a pulmonary exacerbation, there is increased expression of some markers of inflammation and/or lung damage, for example C-reactive protein, white cell counts, interleukin-8, neutrophil elastase alpha 1-antiprotease complexes [15-17] and matrix metalloproteins [18], in blood or serum. Circulating markers may not truly reflect the local inflammatory response in the lung; however, this can be examined by measuring the sputum concentrations of bioactive lipid mediators, such as the cysteinyl leukotrienes and prostaglandin-E2 [19], or sputum cell counts [16] or analysing exhaled breath [20-22] or urine [23] during exacerbations. However, none of these are routinely used in clinical practice.

\section{Impact of exacerbations}

Pulmonary exacerbations have an impact on survival in CF [24, 25], reduce health-related quality of life due to hospitalisation and the associated patient and family dislocation $[24,26]$, adversely affect sleep and neurobehavioral performance [27] and increase health costs [28-30]. Exacerbation rates are often used as one of the outcome measures in studies for new treatments in CF including nebulised Dornase alfa [8], nebulised tobramycin [6], Azithromycin [5], hypertonic saline [9] and Mannitol [31]. The rate of pulmonary exacerbation is also used as an important variable to assess new outcome measures such as high resolution computed tomography of the chest [32] or cough frequency [33] and an important outcome measure when assessing the impact of socioeconomic status [34] and environmental exposure [35] on CF.

\section{Why treat a pulmonary exacerbation?}

Even though the definition of a pulmonary exacerbation is not universally agreed, there is a consensus that acute pulmonary exacerbations should be prevented, where possible, or promptly and aggressively treated where prevention has failed. This is crucial to improving or maintaining lung function, improving quality of life and prolonging survival. As well as causing acute worsening of symptoms, a decline in weight or body mass index and an acute decline in lung function, pulmonary exacerbations also contribute to the long-term deterioration in lung function in patients with CF $[36,37]$. Worryingly, up to a quarter of patients do not recover to baseline within 3 months of treatment of the pulmonary exacerbation with i.v. antibiotics $[37,38]$. Therefore, it is very important that there is an effective approach to early identification and treatment of pulmonary exacerbations.

There is a very early and a high yield of CF pathogens in infants screened by flexible bronchoscopy [39], very early presence of deteriorating structural lung disease associated with worsening inflammation and pulmonary infection $[40,41]$, and abnormal lung function, with increased ventilation inhomogeneity and 
hyperinflation and diminished airway function, in many infants with CF diagnosed through newborn screening by 3 months-old [42]. Despite appearing to be well, these infants should have prompt and aggressive treatment of any abnormal symptoms or signs. There is also a need for prevention of exacerbations. Longitudinal follow-up of this cohort will be essential to ascertain the extent to which early changes in lung function persist throughout the first year of life to see if these is any catch-up growth with conventional treatment. However, in a recent prospective study in infants diagnosed with CF, bronchoalveolar lavage-directed therapy did not result in a lower prevalence of Pseudomonas aeruginosa infection or a lower total CF-computed tomography score when compared with standard therapy at age 5 years [43].

\section{Microbiology of exacerbations \\ Viruses}

Pulmonary exacerbations can be caused by viruses independent of bacterial infections or viruses may be the trigger for bacterial infections [44]. Compared with non-viral exacerbations, virus-related exacerbations are associated with worse severity and quality of life scores, but similar pulmonary inflammation [45]. Influenza A, influenza B and rhinovirus are the mainly implicated viruses, with an annual excess of $2.1 \%$ of exacerbations requiring i.v. antibiotics attributable to influenza $[44,46]$. There is also significant morbidity associated with pandemic influenza infections in CF [47]. The increased morbidity in CF patients after viral infection may be related due to an exaggerated inflammatory response of the airway epithelium as viral exacerbations, especially by Rhinoviruses (RVs), increase planktonic bacterial load, which are in turn more pro-inflammatory than their biofilm counterparts and stimulate an increased chemokine response [48]. An alternative explanation for the increased morbidity in CF patients after viral infections could be linked to increased cell death [49].

Bacteria

Pulmonary exacerbations are usually caused by bacteria which are typically associated with CF (Staphylococcus aureus, Haemophilus influenzae, P. aeruginosa, Burkholderia cepacia complex and other emerging CF pathogens). However, in clinical practice, it is often found that the respiratory tract cultures obtained at the time of exacerbation do not grow the typical bacteria. In a retrospective study looking at 672 admissions over 5 years, $17 \%$ overall were negative for the typical CF bacteria but had signs and symptoms of a pulmonary exacerbation and responded to treatment [50].

S. aureus, $H$. influenzae (nontypeable) and occasionally $S$. pneumoniae are the bacteria most often encountered in pulmonary exacerbations in infancy and early childhood. CF subjects chronically colonised with Methicillin-resistant S. aureus (MRSA) can experience pulmonary exacerbations due to MRSA [51].

Initial infection with $P$. aeruginosa is often environmentally acquired and can be cleared with eradication treatment. Subsequent intermittent isolates can also be eradicated but it eventually becomes an established chronic infection with biofilm formation in most patients. It has been proposed that biofilms play a role in infection persistence and planktonic forms play a role in pulmonary exacerbations. The worsening of symptoms during a pulmonary exacerbation, the proven clinical efficacy of $\beta$-lactam antibiotics in treating exacerbations and the selection for $\beta$-lactam resistance in vivo, suggest that the release of more sensitive planktonic organisms from the biofilm layer play a significant role in pulmonary exacerbations in CF [52]. Pulmonary exacerbations can be associated with the acquisition of new organisms; however, the majority of pulmonary exacerbations are not due to acquisition of new strains of Pseudomonas, but are instead due to clonal expansion of existing strains, especially in adult patients with CF [53].

A change in the bacterial density of colonising flora has also been proposed as another potential mechanism of pulmonary exacerbation, as bacterial concentrations of Pseudomonas were shown to be high during an exacerbation and decreased with treatment with antimicrobial agents (with an associated reduction in symptoms and improvement in lung function) [54, 55]. STRESSMANN et al. [56], however, showed no significant changes either in total bacterial or in $P$. aeruginosa numbers in sputum samples collected at 21, 14,7 and 0 days prior to a pulmonary exacerbation and concluded that pulmonary exacerbations do not generally result from increased bacterial density within the airways. Thus the mechanism(s) of pulmonary exacerbations still remain undetermined and a subject of ongoing investigation.

Culture-independent diagnostic methods (quantitative PCR) have demonstrated that CF sputum specimens generally contain a large number of different bacterial species at high concentrations; however, currently culture-independent diagnostic methods do not offer clinical utility, but may prove useful in clinical trials [57]. 


\section{Nontuberculous mycobacteria}

When nontuberculous mycobacteria (NTM) are isolated from the respiratory secretions of patients with CF, it is unclear whether this represents contamination, colonisation or indeed infection. The American Thoracic Society/Infectious Diseases Society of America has published diagnostic criteria for NTM lung disease that includes the clinical, radiographic, and microbiological criteria which must be met to make a diagnosis of NTM lung disease [58]. Infection with Mycobacterium abscessus, has been shown to be associated with fever and systemic upset [59]. Chronic $M$ abscessus infection is associated with decline in lung function [60] and rapid progression of lung disease. Evidence for NTM infection should be looked for, especially if there is unexplained deterioration or lack of expected improvement with appropriate i.v. antibiotics. Treatment of $M$ abscessus infection would entail initial induction therapy with i.v. amikacin, in combination with i.v. meropenem or i.v. cefoxitin and clarithromycin, for a minumum of 3-4 weeks. Maintenance therapy with nebulised amikacin, oral clarithromycin and another agent to which the organism is sensitive, is recommended [61].

Fungi

Allergic bronchopulmonary aspergillosis (ABPA) should be suspected if there is a poor response to i.v. antibiotics, markedly increased or new-onset wheeze or pleuritic chest pain. The diagnosis needs to be confirmed by radiological and serological testing, as per the UK Cystic Fibrosis Trust 2002 [61] or US Cystic Fibrosis Foundation 2003 diagnostic criteria [62]. Aspergillus may also cause symptoms of pulmonary exacerbation without associated allergic response aspergillus bronchitis [63]. Differentiating between colonisation of the airways by aspergillus, sensitisation and ABPA can be difficult as the clinical, radiological, serological and microbiological features of ABPA can overlap with those seen in CF without ABPA, particularly during a pulmonary exacerbation. Newer diagnostic tests have been evaluated for their performance in differentiating CF with and without ABPA, and diagnosis of ABPA before clinical symptoms arise, as well as to monitor disease activity. These include a panel of recombinant Aspergillus fumigatus allergens (Asp f1, Asp f2, Asp f3, Asp f4 and Asp f6); IgG subclass antibodies (Af-IgG1, Af-IgG2, Af-IgG4, and Af-IgG3) against aspergillus; thymus- and activation-regulated chemokine (TARC); and the cellular allergen stimulation test (CAST). However, these are not widely available and further studies involving a larger number of patients are required for further evaluation, before these tests become a routine investigation for ABPA [62]. The role of Candida in CF lung disease remains unclear, but it may presage pulmonary exacerbation [64].

\section{Treatment strategies}

Even though there is lack of consensus for defining a pulmonary exacerbation, early and optimal treatment is critical in improving the quality and length of life for patients with CF. The whole CF multidisciplinary team including the doctors, specialist nurses, physiotherapist, dietician, pharmacist, clinical psychologist, microbiologist and social worker should work together to evaluate and treat the pulmonary exacerbations and associated complications (e.g. pneumothorax or haemoptysis). Even though exacerbations may occur even with optimum adherence to maintenance treatment (for example inhaled antibiotics and airway clearance), non-adherence because of overall treatment burden, lack of understanding of the importance of the maintenance or complex psychosocial factors can lead to an exacerbation. All efforts must be made by the multidisciplinary team during and after the exacerbation to continue to improve adherence [65].

\section{Anti-infection treatment}

For presumed upper respiratory viral infections, accompanied by a persistent cough for more than 3-5 days or other lower respiratory symptoms, it is common practice to start an oral antibiotic [61], which will cover both $H$. influenzae and S. aureus (e.g. co-amoxiclav). A cough (oropharyngeal) swab or sputum should be taken for culture of CF pathogens before commencing the antibiotic. This is an effective treatment strategy for outpatient management of "mild" acute CF pulmonary exacerbations with a high success rate in terms of eradication of the bacteria and/or symptom resolution [66-68].

However, i.v. antibiotics should be considered if new symptoms develop while undergoing treatment or a positive culture does not clear after the treatment. Multiple courses of oral antibiotics have been shown to be less likely to avert progression to i.v. therapy when the initial course is unsuccessful [69]. In this situation, treatment should be intensified with i.v. antibiotics, as well as more intensive physiotherapy, preferably as an inpatient.

Most CF clinicians will use anti-pseudomonal antibiotics in those patients who have previously grown Pseudomonas, although they may not grow it during the current exacerbation. For patients who have an established chronic Pseudomonas infection and who develop new or increased symptoms at times of upper 
respiratory infections, a 2-week course of ciprofloxacin may be given, along with continuation of their regular nebulised anti-pseudomonal antibiotic [61].

When the pulmonary exacerbation requires treatment with i.v. antibiotics, despite the theoretical advantage of enhanced antibiotic exposure by both the inhaled and systemic route, this combined approach does not seem to improve outcomes in terms of better or faster clinical improvement, though sputum counts of Pseudomonas were lower [70]. There is a potential for increased toxicity following systemic absorption of inhaled antibiotics and it also makes the interpretation of serum levels of some antibiotics more difficult. Thus, there is insufficient evidence to recommend continuation of an inhaled anti-pseudomonal antibiotic in conjunction with the same i.v. antibiotic during an exacerbation, and consensus guidelines suggest that this decision should be determined on a case-by-case basis [14].

There are variations in the decision to commence i.v. antibiotics [7]. When site-specific variations in practice patterns were analysed, it was found that CF care sites with patients who have the best lung function prescribe i.v. antibiotics more frequently than sites with patients who have a lower average forced expiratory volume in $1 \mathrm{~s}(\mathrm{FEV} 1)$ [71].

The decision to treat the pulmonary exacerbation with i.v. antibiotics does not necessarily entail a hospital admission. There are variations in the availability of home i.v. antibiotic services and the level of patient monitoring across the UK [72]. It should be emphasised to patients and carers that i.v. antibiotics are only one part of the treatment of a pulmonary exacerbation, other interventions include intensive and supervised chest physiotherapy and airway clearance, nutritional supplementation, possible treatment of CF-related diabetes and antibiotic level monitoring. There is conflicting evidence in terms of outcomes based on the location of treatment; some studies suggest better outcomes for patients treated in a hospital than for those treated at home [73-76], while others report equivalence in terms of in terms of long-term FEV1 change and the interval between courses of antibiotics [77]. Consensus guidelines [14] do not recommend delivery of i.v. antibiotics in a non-hospital setting, unless resources and support equivalent to the hospital setting can be assured for the treatment of a pulmonary exacerbation (although in clinical practice, treatment will often get started in hospital and part of the course is then completed at home).

\section{Antibiotic choice}

Conventionally, antibiotic selection for treatment of pulmonary exacerbations has been directed by the results of antibiotic susceptibility testing $[14,65]$. However, there is uncertainty regarding the state in which the organisms exist within the CF lung and the antibiotic susceptibilities of the organisms growing in planktonic, adherent and biofilm states vary significantly [78]. There is mounting evidence questioning the utility of routine antibiotic susceptibility testing [79].

A combination of anti-pseudomonal antibiotics should be used as far as possible, with different mechanism of actions for treatment of pulmonary exacerbations with Pseudomonas; typically this would be an aminoglycoside in combination with a $\beta$-lactam antibiotic. When using aminoglycoside antibiotics, it is now common practice to use once daily dosing [80], while the $\beta$-lactam antibiotics are recommended to be administered by intermittent rather than continuous infusion [14]. The CF Foundation recommends against the use of synergy testing as part of the routine evaluation of a patient with an acute pulmonary exacerbation caused by multidrug-resistant bacteria [14]. For pulmonary exacerbations in those subjects who have chronic MRSA infection intravenous teicoplanin or vancomycin should be used [61].

\section{Duration}

A minimum duration of 10 days has been recommended for antibiotic treatment [61]. A recent large multicentre retrospective study indicated that improvement in FEV1 plateaus after 7-10 days of therapy [77]; however, whether i.v. antibiotic treatment for $>14$ days leads to sustained clinical benefit is difficult to ascertain, and use of lung function as a guide could be unhelpful. In one study, parents and children felt that the third week was subjectively beneficial [81]. Most clinicians will, however, use 2 weeks of treatment as a routine, although there is no evidence from randomised studies as to the optimal duration of treatment [14]. Duration of treatment is currently based on unit policies and response to treatment. Shorter duration of treatment should improve quality of life and compliance, result in a reduced incidence of drug reactions and be less costly. However, this may not be sufficient to clear a chest infection and may result in an early recurrence of a pulmonary exacerbation [82].

Despite appropriate treatment, there are treatment failures in up to a quarter of CF pulmonary exacerbations $[37,38,83]$, which could be either failure to recover to base line, a change in antibiotic regimen, prolonging the duration of treatment, or early recurrence. Some of the factors associated with these treatment failures include advanced airway disease, use of enteric feeds, CF-related diabetes, CF-liver disease and increased markers of inflammation. 
Repeated courses of antibiotics can lead to development of hypersensitivity reactions in some individuals with $\mathrm{CF}$ and they may require desensitisation for each course of treatment [61].

\section{Viral infections}

Neuraminidase inhibitors limit infection and prevent spread of the influenza virus, but there are no trials to support or refute their use in CF [84]. However, it is rational to use them in high-risk populations like CF, although deterioration in pulmonary status can happen despite Oseltamivir therapy [47].

\section{Airway clearance}

This should be intensified during a pulmonary exacerbation using a range of physiotherapy techniques, including positive end expiratory pressure techniques and occasionally the use of the Bird ventilator [65]. In patients hospitalised with a severe pulmonary exacerbation, early use of noninvasive ventilation may prevent the worsening of the respiratory status [85]. The opportunity to review physiotherapy techniques and provide education on airway clearance should be taken during a pulmonary exacerbation.

\section{Airway surface liquid hydrators/mucolytics}

Airway surface hydrators like nebulised hypertonic saline [86] and inhaled mannitol [87] improve mucociliary clearance when used for periods of 2-4 weeks. Nebulised hypertonic saline may have antiinflammatory properties [88] and improves some measurements of lung function (like lung clearance index [89], as well as FEV1 at 4 weeks [90], although this mild improvement in FEV1 is not sustained at 48 weeks). For the above reasons, nebulised hypertonic saline is being increasingly used as an adjunct to physiotherapy during pulmonary exacerbations. During acute pulmonary exacerbation, Dornase alfa appears to be safe and well tolerated but does not show a statistically significant therapeutic effect when added to antibiotics and physiotherapy [91]. However, bronchoscopic instillation of Dornase alfa has been used successfully for lobar atelectasis in CF, which is unresponsive to medical therapy [92].

\section{Management of comorbidities}

Increased energy requirements, because of a catabolic state combined with reduced appetite and vomiting secondary to swallowed sputum, makes it very important that nutritional support is optimised. Insulin requirements can increase up to four times the usual baseline insulin dosage needed in some CF-related diabetes patients and will need to be reduced once the pulmonary exacerbation is treated [93].

Oral corticosteroids are the mainstay for treatment of ABPA. Therapy is started with oral prednisolone at $0.5-1 \mathrm{mg} \cdot \mathrm{kg}^{-1} \cdot \mathrm{day}^{-1}$ (daily maximum of $60 \mathrm{mg}$ ) for $1-2$ weeks, then $0.5-1 \mathrm{mg} \cdot \mathrm{kg}^{-1} \cdot \mathrm{day}^{-1}$ every other day for 1-2 weeks, then taper off in 2-3 months on the basis of IgE, chest radiography, spirometry and pulmonary symptoms. Antifungal therapy with itraconazole should be added if there is a slow or poor response to corticosteroids, for relapse of ABPA, in corticosteroid-dependent ABPA and in cases of corticosteroid toxicity. The use of antifungal therapy is recommended by a number of national clinical guidelines $[61,94]$, despite the fact there are no large randomised controlled trials supporting the use of antifungals in combination with oral corticosteroids. Oral itraconazole is poorly absorbed by persons with $\mathrm{CF}$, particularly children, and measurement of serum itraconazole levels should be considered when there is a lack of clinical response or if there is concern about adequate drug absorption or patient compliance. The initial dose of itraconazole should be $5 \mathrm{mg} \cdot \mathrm{kg}^{-1} \cdot \mathrm{day}^{-1}$, which may be given once daily unless the dose exceeds $200 \mathrm{mg} \cdot$ day $^{-1}$, in which case it should be given twice daily. The daily dose should not exceed $400 \mathrm{mg} \cdot \mathrm{day}^{-1}$ unless low serum itraconazole levels are obtained. The bioavailability of itraconazole is better when given as an oral solution, compared with capsules [95], or when it is given along with a vitamin C drink [96] or with a carbonated soft drink [61]. Even when used at the recommended doses, therapeutic levels may not be achieved [97]. The use of Voricoanzole in treatment of ABPA, as an alternative to itraconazole as it has better bioavailability $[98,99]$, requires caution in view of the phototoxicity and strict photoprotection should be advised [100, 101]. Nebulised liposomal Amphotericin B with [102] or without [103] nebulised corticosteroids as an alternative treatment in ABPA has been reported with anecdotal success. The duration of therapy should be 3-6 months [61].

The short-term use of oral steroids during a pulmonary exacerbation may be beneficial, but there is insufficient evidence to recommend the routine use of corticosteroids in its treatment [14].

\section{Strategies to prevent or reduce pulmonary exacerbations \\ Prophylactic antibiotics \\ Staphylococcus aureus}

Prophylactic flucloxacillin is commenced from diagnosis and continued for the first 3 years in the UK [61]. However, a Cochrane review did not show any significant differences in hospital admissions or additional 
courses of antibiotics required between the two groups receiving either regular antibiotics or intermittent courses, as required [104]. For CF subjects who isolate MRSA for the first time or who have been free of MRSA following previous treatment, eradication should be attempted. The regimen should include topical treatment with nasal mupirocin, chlorhexidine bath wash and either combination oral therapy with rifampicin and fusidic acid or nebulised vancomycin or a combination of all three [61].

\section{Pseudomonas aeruginosa}

A "preventive" antibiotic strategy against $P$. aeruginosa is not routine practice. 3-monthly cycled anti- $P$. aeruginosa prophylaxis was shown not to reduce the risk of initial and chronic infection in $P$. aeruginosanegative children with CF of all ages [105]. As opposed to "preventive" therapy for P. aeruginosa, early aggressive eradication is universally recommended and may be sustained in the short-term, up to 12 months [106]. Available evidence supports the use of nebulised antibiotics, alone (tobramycin solution for inhalation) or in combination with (nebulised colisitin) with oral ciprofloxacin. Despite the universal consensus on aggressive eradication treatment for P. aeruginosa, the optimal regimen is a subject of ongoing investigation [106]. Having successfully eradicated the initial $P$. aeruginosa, close microbiological monitoring of airway cultures in young patients with CF recently infected with $P$. aeruginosa is recommended; regular cycles of therapy do not offer an improved chance of remaining free of $P$. aeruginosa [107]. Children with CF who fail to eradicate the P. aeruginosa after initial antibiotic treatment are at higher risk of subsequent pulmonary exacerbations [108]. These intermittent isolates could have been picked up in routine microbiological surveillance, or may have been the reason for a pulmonary exacerbation. Once

TABLE 1 Maintenance pulmonary treatment and reduction in pulmonary exacerbations

Intervention lapproximate Subjects $n \quad$ Age years $\begin{gathered}\text { Duration of } \\ \text { intervention }\end{gathered}$
reduction)

\begin{tabular}{|c|c|c|c|c|}
\hline $\begin{array}{l}\text { Inhaled Tobramycin } \\
\text { solution } 300 \text { mg twice }\end{array}$ & 520 & 21 & 24 weeks & $\begin{array}{l}26 \%(2-43 \%) \text { less likely to be hospitalised and } 36 \%(17-51 \%) \text { less } \\
\text { likely to require i.v. anti-pseudomonal antibiotics [6] }\end{array}$ \\
\hline $\begin{array}{l}\text { daily, } 4 \text { weeks on, } \\
4 \text { weeks off (quarter) }\end{array}$ & 128 & $13-17$ & 2 years & $\begin{array}{l}\text { Number of hospital admissions reduced by } 19 \% \text { and i.v. antibiotic } \\
\text { courses per patient year reduced by } 32 \% \text { [112] }\end{array}$ \\
\hline \multirow[t]{2}{*}{$\begin{array}{l}\text { DNAse } 2.5 \mathrm{mg} \text { twice or } \\
\text { once daily (third) }\end{array}$} & 968 & $\geqslant 5$ & 24 weeks & $\begin{array}{l}\text { Risk of a PEx requiring parenteral antibiotic therapy reduced } 28 \% \\
(2-48 \%) \text { for once daily and } 37 \%(13-54 \%) \text { for twice daily [8] }\end{array}$ \\
\hline & 474 & $6-10$ & 96 weeks & Risk of PEx reduced by $34 \%(0-56 \%)$ [113] \\
\hline Ibuprofen $20-30 \mathrm{mg} \cdot \mathrm{kg}^{-1}$ & 85 & $5-39$ & 4 years & Fewer hospital admissions Peto OR 0.64 (95\% Cl 0.39-1.05) [114] \\
\hline
\end{tabular}

to a maximum of $1600 \mathrm{mg}$ in two divided doses (third)

Mannitol $400 \mathrm{mg}$ inhaled dry powder mannitol twice daily (third)

Azithromycin $250 \mathrm{mg}$ patients $<\mathbf{4 0} \mathbf{~ k g}$ and $500 \mathrm{mg}$ patients $>\mathbf{4 0} \mathbf{~ k g}$ three times a week (half)

\section{Nebulised hypertonic saline $7 \% 4 \mathrm{~mL}$ twice daily (half)}

\begin{tabular}{|c|c|c|c|}
\hline & 321 & $\begin{array}{l}\text { 4-60 } \\
\text { months }\end{array}$ & 48 weeks \\
\hline $\begin{array}{l}\text { Ivacaftor } 150 \mathrm{mg} \text { every } \\
12 \mathrm{~h} \text { (half) }\end{array}$ & 161 & $\begin{array}{c}\geqslant 12 \text { (with } \\
\text { at least one } \\
\text { G551D CFTR } \\
\text { mutation) }\end{array}$ & 48 weeks \\
\hline
\end{tabular}

48 weeks
26 weeks

6 months

Insufficient evidence [119]

Insufficient evidence [120]

Data are presented as $\mathrm{n}$ or $\%(95 \% \mathrm{CI})$, unless otherwise stated. PEx: pulmonary exacerbation; CFTR: cystic fibrosis transmembrane conductance regulator. 
chronic infection with $P$. aeruginosa is established, there is increased morbidity, including increased hospitalisation and increased need for treatment. Hence, it is imperative to aggressively treat initial isolates of $P$. aeruginosa to achieve eradication and delay establishment of chronic infection.

Other bacteria

No preventive antibiotic treatment strategies are currently recommended for other established (e.g. H. influenzae, Burkholderia cepacia complex) or emerging (e.g. Stenotrophomonas maltophilia, Achromobacter xylosidans) CF bacteria.

\section{Infection control}

CF infection control strategies, including segregation based on microbiological status, hand hygiene for staff and patients, contact and droplet precautions for certain pathogens and disinfecting equipment and surfaces, are rigorously observed in all clinical settings involving CF patients, to prevent spread of infections from patient to patient [109].

\section{Immunisations}

Children with CF should receive their routine childhood immunisations, but additional vaccines are also recommended, including annual influenza vaccination. However, a Cochrane review [110] concluded that there is currently no evidence from randomised studies that influenza vaccines given to people with CF are of benefit to them. H1N1 influenza also causes significant morbidity in most of the patients with CF, with respiratory deterioration in some [47]. Again, annual vaccination is now recommended as routine. There is insufficient evidence to support Palivizumab or anti-pseudomonal vaccines [111].

\section{Maintenance pulmonary treatment to reduce exacerbations}

Pulmonary exacerbation rate is often used as a primary or secondary end-point in clinical trials for new interventions in CF. Maintenance pulmonary treatments lead to reduction in pulmonary exacerbation rates and the efficacy of different interventions in reducing the pulmonary exacerbation rate is summarised in table 1. Lack of adherence to maintenance treatment, including physiotherapy (fig. 1), is likely to be multifactorial, with factors including a large treatment burden or lack of understanding of the importance of this treatment. As pulmonary exacerbations may still occur even with optimum adherence, it is important to reassure parents and for patients to continue maintenance therapies [121, 122]. In terms of antibiotic maintenance treatment, the prevalence of inhaled antibiotic use in the North American CF population increased during the period from 1996 to 2005 due to increased chronic use, while acute use to treat pulmonary exacerbations decreased [123].

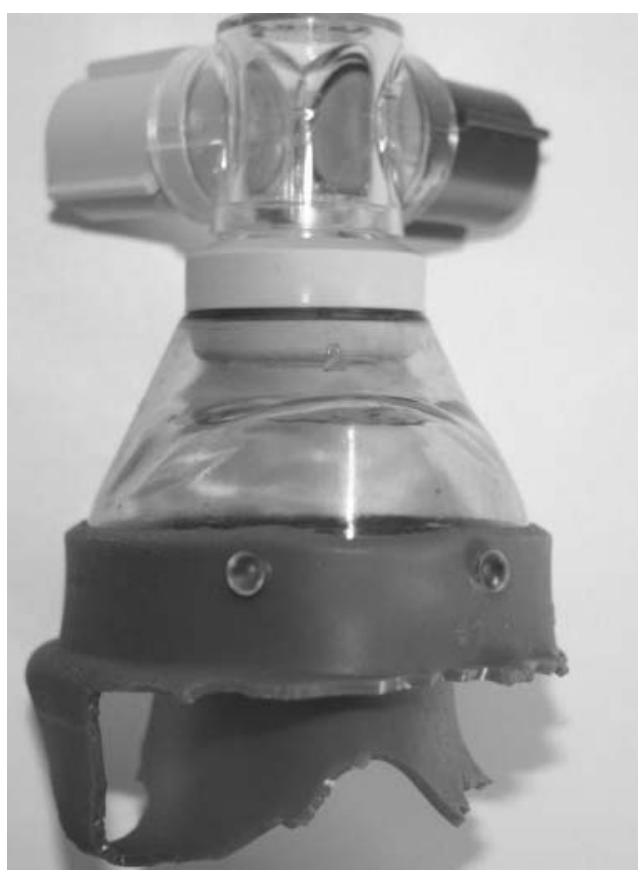

FIGURE 1 A chewed up positive expiratory pressure mask which the young person was meant to be using for physiotherapy. 


\section{Conclusions}

Pulmonary exacerbations have very important consequences in CF, both in terms of current morbidity, as well as implications for long term morbidity and mortality. Even though there is no universally agreed definition of a pulmonary exacerbation, prompt and aggressive treatment with a multidisciplinary approach is recommended. Maintenance treatments reduce the risk of pulmonary exacerbations. Antibiotics should be targeted against the common CF bacteria and these could be given orally, but i.v. antibiotics will be required for ongoing symptoms or severe pulmonary exacerbations. Management of comorbidities, like poor nutrition and diabetes, will be critical in improving outcomes.

\section{References}

1 Cystic Fibrosis Trust. UK CF Registry Annual data report 2010. www.cysticfibrosis.org.uk/media/108230/ CR_Annual_Data_Report_2010_Dec_11.pdf Date last accessed: April 23, 2012. Date last updated: December 14, 2011.

2 FitzGerald JM. Targeting lung attacks. Thorax 2011; 66: 365-366.

3 Dakin C, Henry RL, Field P, et al. Defining an exacerbation of pulmonary disease in cystic fibrosis. Pediatr Pulmonol 2001; 31: 436-442.

4 Cunningham JC, Taussig LM. An Introduction to Cystic Fibrosis for Patients and Families. 5th Edn. Cystic Fibrosis Foundation, 2003. www.cff.org/uploadedfiles/treatments/cfcareguidelines/diagnosis/an-introduction-to-cf-for-patientsand-families.pdf Date last accessed April 23, 2012.

5 Saiman L, Marshall BC, Mayer-Hamblett N, et al. Azithromycin in patients with cystic fibrosis chronically infected with Pseudomonas aeruginosa: a randomized controlled trial. JAMA 2003; 290: 1749-1756.

6 Ramsey BW, Pepe MS, Quan JM, et al. Intermittent administration of inhaled tobramycin in patients with cystic fibrosis. Cystic Fibrosis Inhaled Tobramycin Study Group. N Engl J Med 1999; 340: $23-30$.

$7 \quad$ Kraynack NC, Gothard MD, Falletta LM, et al. Approach to treating cystic fibrosis pulmonary exacerbations varies widely across US CF care centers. Pediatr Pulmonol 2011; 46: 870-881.

8 Fuchs HJ, Borowitz DS, Christiansen DH, et al. Effect of aerosolized recombinant human DNase on exacerbations of respiratory symptoms and on pulmonary function in patients with cystic fibrosis. The Pulmozyme Study Group. N Engl J Med 1994; 331: 637-642.

9 Elkins MR, Robinson M, Rose BR, et al. A controlled trial of long-term inhaled hypertonic saline in patients with cystic fibrosis. N Engl J Med 2006; 354: 229-240.

10 Treggiari MM, Rosenfeld M, Mayer-Hamblett N, et al. Early anti-pseudomonal acquisition in young patients with cystic fibrosis: rationale and design of the EPIC clinical trial and observational study. Contemp Clin Trials 2009; 30: 256-268.

11 Rabin HR, Butler SM, Wohl ME, et al. Pulmonary exacerbations in cystic fibrosis. Pediatr Pulmonol 2004; 37: 400-406.

12 Regelmann WE, Schechter MS, Wagener JS, et al. Pulmonary exacerbations in cystic fibrosis: young children with characteristic signs and symptoms. Pediatr Pulmonol 2012 [In press DOI: 10.1002/ppul.22658].

13 Bilton D, Canny G, Conway S, et al. Pulmonary exacerbation: towards a definition for use in clinical trials. Report from the EuroCareCF Working Group on outcome parameters in clinical trials. J Cyst Fibros 2011; 10: Suppl. 2, S79-S81.

14 Flume PA, Mogayzel PJ Jr, Robinson KA, et al. Cystic fibrosis pulmonary guidelines: treatment of pulmonary exacerbations. Am J Respir Crit Care Med 2009; 180: 802-808.

15 McGrath LT, Mallon P, Dowey L, et al. Oxidative stress during acute respiratory exacerbations in cystic fibrosis. Thorax 1999; 54: 518-523.

16 Downey DG, Brockbank S, Martin SL, et al. The effect of treatment of cystic fibrosis pulmonary exacerbations on airways and systemic inflammation. Pediatr Pulmonol 2007; 42: 729-735.

17 Wieboldt J, Atallah L, Kelly JL, et al. Effect of acute exacerbations on skeletal muscle strength and physical activity in cystic fibrosis. J Cyst Fibros 2012; 11: 209-215.

18 Roderfeld M, Rath T, Schulz R, et al. Serum matrix metalloproteinases in adult CF patients: relation to pulmonary exacerbation. J Cyst Fibros 2009; 8: 338-347.

19 Reid DW, Misso N, Aggarwal S, et al. Oxidative stress and lipid-derived inflammatory mediators during acute exacerbations of cystic fibrosis. Respirology 2007; 12: 63-69.

20 Robroeks CM, Rosias PP, van Vliet D, et al. Biomarkers in exhaled breath condensate indicate presence and severity of cystic fibrosis in children. Pediatr Allergy Immunol 2008; 19: 652-659.

21 Bodini A, D'Orazio C, Peroni D, et al. Biomarkers of neutrophilic inflammation in exhaled air of cystic fibrosis children with bacterial airway infections. Pediatr Pulmonol 2005; 40: 494-499.

22 Bodini A, D'Orazio C, Peroni DG, et al. IL-8 and pH values in exhaled condensate after antibiotics in cystic fibrosis children. Int J Immunopathol Pharmacol 2007; 20: 467-472.

23 Laguna TA, Wagner BD, Starcher B, et al. Urinary desmosine: a biomarker of structural lung injury during CF pulmonary exacerbation. Pediatr Pulmonol 2012; 47: 856-863.

24 Liou TG, Adler FR, Fitzsimmons SC, et al. Predictive 5-year survivorship model of cystic fibrosis. Am J Epidemiol 2001; 153: 345-352.

25 Simmonds NJ, Macneill SJ, Cullinan P, et al. Cystic fibrosis and survival to 40 years: a case-control study. Eur Respir J 2010; 36: 1277-1283.

26 Britto MT, Kotagal UR, Hornung RW, et al. Impact of recent pulmonary exacerbations on quality of life in patients with cystic fibrosis. Chest 2002; 121: 64-72.

27 Dobbin CJ, Bartlett D, Melehan K, et al. The effect of infective exacerbations on sleep and neurobehavioral function in cystic fibrosis. Am J Respir Crit Care Med 2005; 172: 99-104.

28 Robson M, Abbott J, Webb K, et al. A cost description of an adult cystic fibrosis unit and cost analyses of different categories of patients. Thorax 1992; 47: 684-689. 
Lieu TA, Ray GT, Farmer G, et al. The cost of medical care for patients with cystic fibrosis in a health maintenance organization. Pediatrics 1999; 103: e72.

30 Ouyang L, Grosse SD, Amendah DD, et al. Healthcare expenditures for privately insured people with cystic fibrosis. Pediatr Pulmonol 2009; 44: 989-996.

31 Bilton D, Robinson P, Cooper P, et al. Inhaled dry powder mannitol in cystic fibrosis: an efficacy and safety study. Eur Respir J 2011; 38: 1071-1080.

32 Brody AS, Sucharew H, Campbell JD, et al. Computed tomography correlates with pulmonary exacerbations in children with cystic fibrosis. Am J Respir Crit Care Med 2005; 172: 1128-1132.

33 Smith JA, Owen EC, Jones AM, et al. Objective measurement of cough during pulmonary exacerbations in adults with cystic fibrosis. Thorax 2006; 61: 425-429.

34 Schechter MS, McColley SA, Silva S, et al. Association of socioeconomic status with the use of chronic therapies and healthcare utilization in children with cystic fibrosis. J Pediatr 2009; 155: 634-639.

35 Goss CH, Newsom SA, Schildcrout JS, et al. Effect of ambient air pollution on pulmonary exacerbations and lung function in cystic fibrosis. Am J Respir Crit Care Med 2004; 169: 816-821.

36 Konstan MW, Morgan WJ, Butler SM, et al. Risk factors for rate of decline in forced expiratory volume in one second in children and adolescents with cystic fibrosis. J Pediatr 2007; 151: 134-139.

37 Sanders DB, Bittner RC, Rosenfeld M, et al. Pulmonary exacerbations are associated with subsequent FEV1 decline in both adults and children with cystic fibrosis. Pediatr Pulmonol 2011; 46: 393-400.

38 Sanders DB, Bittner RC, Rosenfeld M, et al. Failure to recover to baseline pulmonary function after cystic fibrosis pulmonary exacerbation. Am J Respir Crit Care Med 2010; 182: 627-632.

39 Stafler P, Davies JC, Balfour-Lynn IM, et al. Bronchoscopy in cystic fibrosis infants diagnosed by newborn screening. Pediatr Pulmonol 2011; 46: 696-700.

40 Pillarisetti N, Williamson E, Linnane B, et al. Infection, inflammation, and lung function decline in infants with cystic fibrosis. Am J Respir Crit Care Med 2011; 184: 75-81.

41 Mott LS, Park J, Murray CP, et al. Progression of early structural lung disease in young children with cystic fibrosis assessed using CT. Thorax 2012; 67: 509-516.

42 Hoo AF, Thia LP, Nguyen TT, et al. Lung function is abnormal in 3-month-old infants with cystic fibrosis diagnosed by newborn screening. Thorax 2012; 67: 874-881.

43 Wainwright CE, Vidmar S, Armstrong DS, et al. Effect of bronchoalveolar lavage-directed therapy on Pseudomonas aeruginosa infection and structural lung injury in children with cystic fibrosis: a randomized trial. JAMA 2011; 306: $163-171$.

44 Wat D, Gelder C, Hibbitts S, et al. The role of respiratory viruses in cystic fibrosis. J Cyst Fibros 2008; 7: 320-328.

45 Asner S, Waters V, Solomon $\mathrm{M}$, et al. Role of respiratory viruses in pulmonary exacerbations in children with cystic fibrosis. J Cyst Fibros 2012; 11: 433-439.

46 Ortiz JR, Neuzil KM, Victor JC, et al. Influenza-associated cystic fibrosis pulmonary exacerbations. Chest 2010; 137: 852-860.

47 Viviani L, Assael BM, Kerem E. Impact of the A (H1N1) pandemic influenza (season 2009-2010) on patients with cystic fibrosis. J Cyst Fibrosis 2011; 10: 370-376.

48 Chattoraj SS, Ganesan S, Jones AM, et al. Rhinovirus infection liberates planktonic bacteria from biofilm and increases chemokine responses in cystic fibrosis airway epithelial cells. Thorax 2011; 66: 333-339.

49 Kieninger E, Vareille M, Kopf BS, et al. Lack of an exaggerated inflammatory response on virus infection in cystic fibrosis. Eur Respir J 2012; 39: 297-304.

50 Zemanick ET, Wagner BD, Harris JK, et al. Pulmonary exacerbations in cystic fibrosis with negative bacterial cultures. Pediatr Pulmonol 2010; 45: 569-577.

51 Miall LS, McGinley NT, Brownlee KG, et al. Methicillin resistant Staphylococcus aureus (MRSA) infection in cystic fibrosis. Arch Dis Child 2001; 84: 160-162.

52 Van Devanter DR, Van Dalfsen JM. How much do Pseudomonas biofilms contribute to symptoms of pulmonary exacerbation in cystic fibrosis? Pediatr Pulmonol 2005; 39: 504-506.

53 Aaron SD, Ramotar K, Ferris W, et al. Adult cystic fibrosis exacerbations and new strains of Pseudomonas aeruginosa. Am J Respir Crit Care Med 2004; 169: 811-815.

54 Smith AL, Redding G, Doershuk C, et al. Sputum changes associated with therapy for endobronchial exacerbation in cystic fibrosis. J Pediatr 1988; 112: 547-554.

55 Regelmann WE, Elliott GR, Warwick WJ, et al. Reduction of sputum Pseudomonas aeruginosa density by antibiotics improves lung function in cystic fibrosis more than do bronchodilators and chest physiotherapy alone. Am Rev Respir Dis 1990; 141: 914-921.

56 Stressmann FA, Rogers GB, Marsh P, et al. Does bacterial density in cystic fibrosis sputum increase prior to pulmonary exacerbation? J Cyst Fibros 2011; 10: 357-365.

57 Döring G, Flume P, Heijerman H, et al. Treatment of lung infection in patients with cystic fibrosis: current and future strategies. J Cyst Fibros 2012; 11: 461-479.

58 Griffith DE, Aksamit T, Brown-Elliott BA, et al. An official ATS/IDSA statement: diagnosis, treatment, and prevention of nontuberculous mycobacterial diseases. Am J Respir Crit Care Med 2007; 175: 367-416.

59 Cullen AR, Cannon CL, Mark EJ, et al. Mycobacterium abscessus infection in cystic fibrosis. Colonization or infection? Am J Respir Crit Care Med 2000; 161: 641-645.

60 Esther CR Jr, Esserman DA, Gilligan P, et al. Chronic Mycobacterium abscessus infection and lung function decline in cystic fibrosis. J Cyst Fibrosis 2010; 9: 117-123.

61 Cystic Fibrosis Trust. Antibiotic treatment for cystic fibrosis. Report of the UK Cystic Fibrosis Trust Antibiotic Working Group. 3rd Edn. London, Cystic Fibrosis Trust, 2009.

62 Thia LP, Balfour Lynn IM. Diagnosing allergic bronchopulmonary aspergillosis in children with cystic fibrosis. Paediatr Respir Rev 2009; 10: 37-42.

63 Shoseyov D, Brownlee KG, Conway SP, et al. Aspergillus bronchitis in cystic fibrosis. Chest 2006; 130: $222-226$.

64 Chotirmall SH, O’Donoghue E, Bennett K, et al. Sputum Candida albicans presages FEV1 decline and hospitaltreated exacerbations in cystic fibrosis. Chest 2010; 138: 1186-1195.

65 Smyth A, Elborn JS. Exacerbations in cystic fibrosis: 3 - Management. Thorax 2008; 63: $180-184$. 
66 Szaff M, Høiby N. Antibiotic treatment of Staphylococcus aureus infection in cystic brosis. Acta Paediatr Scand 1982; 71: 821-826.

67 Pressler T, Szaff M, Høiby N. Antibiotic treatment of Haemophilus inuenzae and Haemophilus parainuenzae infections in patients with cystic fibrosis. Acta Paediatr Scand 1984; 73: 541-547.

68 Rayner RJ, Hiller EJ, Ispahani P, et al. Haemophilus infection in cystic brosis. Arch Dis Child 1990; 65: 255-258.

69 Briggs EC, Nguyen T, Wall MA, et al. Oral antimicrobial use in outpatient cystic fibrosis pulmonary exacerbation management: a single-center experience. Clin Respir J 2012; 6: 56-64.

70 Touw DJ, Brimicombe RW, Hodson ME, et al. Inhalation of antibiotics in cystic fibrosis. Eur Respir J 1995; 8: 1594-1604.

71 Johnson C, Butler SM, Konstan MW, et al. Factors influencing outcomes in cystic fibrosis: a center-based analysis. Chest 2003; 123: 20-27.

72 Gilchrist FJ, Lenney W. A review of the home intravenous antibiotic service available to children with cystic fibrosis. Arch Dis Child 2009; 94: 647.

73 Bosworth DG, Nielson DW. Effectiveness of home versus hospital care in the routine treatment of cystic fibrosis. Pediatr Pulmonol 1997; 24: 42-47.

74 Thornton J, Elliott R, Tully MP, et al. Long term clinical outcome and hospital intravenous antibiotic treatment in adults with cystic fibrosis. Thorax 2004; 59: 242-246.

75 Termoz A, Touzet S, Bourdy S, et al. Effectiveness of home treatment for patients with cystic fibrosis: the intravenous administration of antibiotics to treat respiratory infections. Pediatr Pulmonol 2008; 43: 908-915.

76 Nazer D, Abdulhamid I, Thomas R, et al. Home versus hospital intravenous antibiotic therapy for acute pulmonary exacerbations in children with cystic fibrosis. Pediatr Pulmonol 2006; 41: 744-749.

77 Collaco JM, Green DM, Cutting GR, et al. Location and duration of treatment of cystic fibrosis respiratory exacerbations do not affect outcomes. Am J Respir Crit Care Med 2010; 182: 1137-1143.

78 Aaron SD, Ferris W, Ramotar K, et al. Single and combination antibiotic susceptibilities of planktonic, adherent, and biofilm-grown Pseudomonas aeruginosa isolates cultured from sputa of adults with cystic fibrosis. J Clin Microbiol 2002; 40: 4172-4179.

79 Hurley $\mathrm{MN}$, Ariff $\mathrm{AH}$, Bertenshaw C, et al. Results of antibiotic susceptibility testing do not influence clinical outcome in children with cystic fibrosis. J Cyst Fibros 2012; 11: 288-292.

80 Smyth AR, Bhatt J. Once-daily versus multiple-daily dosing with intravenous aminoglycosides for cystic fibrosis. Cochrane Database Syst Rev 2012; 2: CD002009.

81 Brown SM, Balfour-Lynn IM. Duration of intravenous antibiotic treatment for respiratory exacerbations in children with cystic fibrosis. Arch Dis Child 2010; 95: 568.

82 Plummer A, Wildman M. Duration of intravenous antibiotic therapy in people with cystic fibrosis. Cochrane Database Syst Rev 2011; 1: CD006682.

83 Parkins MD, Rendall JC, Elborn JS. Incidence and risk factors for pulmonary exacerbation treatment failures in cystic fibrosis patients chronically infected with Pseudomonas aeruginosa. Chest 2012; 141: 485-493.

84 Jagannath VA, Asokan GV, Fedorowicz Z, et al. Neuraminidase inhibitors for the treatment of influenza infection in people with cystic fibrosis. Cochrane Database Syst Rev 2010; 3: CD008139.

85 Fauroux B. Why, when and how to propose noninvasive ventilation in cystic fibrosis? Minerva Anestesiol 2011; 77: $1108-1114$.

86 Donaldson SH, Bennett WD, Zeman KL, et al. Mucus clearance and lung function in cystic fibrosis with hypertonic saline. N Engl J Med 2006; 354: 241-250.

87 Daviskas E, Anderson SD, Jaques A, et al. Inhaled mannitol improves the hydration and surface properties of sputum in patients with cystic fibrosis. Chest 2010; 137: 861-868.

88 Reeves EP, Williamson M, O’Neill SJ, et al. Nebulized hypertonic saline decreases IL-8 in sputum of patients with cystic fibrosis. Am J Respir Crit Care Med 2011; 183: 1517-1523.

89 Amin R, Subbarao P, Jabar A, et al. Hypertonic saline improves the LCI in paediatric patients with CF with normal lung function. Thorax 2010; 65: 379-383.

90 Wark P, McDonald VM. Nebulised hypertonic saline for cystic fibrosis. Cochrane Database Syst Rev 2009; 2 : CD001506.

91 Wilmott RW, Amin RS, Colin AA, et al. Aerosolized recombinant human DNase in hospitalized cystic fibrosis patients with acute pulmonary exacerbations. Am J Respir Crit Care Med 1996; 153: 1914-1917.

92 Slattery DM, Waltz DA, Denham B, et al. Bronchoscopically administered recombinant human DNase for lobar atelectasis in cystic fibrosis. Pediatr Pulmonol 2001; 31: 383-388.

93 Moran A, Hardin D, Rodman D, et al. Diagnosis, screening and management of cystic fibrosis related diabetes mellitus: a consensus conference report. Diabetes Res Clin Pract 1999; 45: 61-73.

94 Stevens DA, Moss RB, Kurup VP, et al. Allergic bronchopulmonary aspergillosis in cystic fibrosis - state of the art: Cystic Fibrosis Foundation Consensus Conference. Clin Infect Dis 2003; 37: Suppl. 3, S225-S264.

95 Barone JA, Moskovitz BL, Guarnieri J, et al. Enhanced bioavailability of itraconazole in hydroxypropyl- $\beta$ cyclodextrin solution versus capsules in healthy volunteers. Antimicrob Agents Chemother 1998; 42: 1862-1865.

96 Bae SK, Park SJ, Shim EJ, et al. Increased oral bioavailability of itraconazole and its active metabolite, 7-hydroxyitraconazole, when coadministered with a vitamin C beverage in healthy participants. J Clin Pharmacol 2011; 51: 444-451.

97 Bentley S, Gupta A, Balfour-Lynn IM. Subtherapeutic itraconazole and voriconazole levels in children with cystic fibrosis. J Cyst Fibros 2013; 12: 418-419.

98 Hilliard T, Edwards S, Buchdahl R, et al. Voriconazole therapy in children with cystic fibrosis. J Cyst Fibros 2005; 4: 215-220.

99 Glackin L, Leen G, Elnazir B, et al. Voriconazole in the treatment of allergic bronchopulmonary aspergillosis in cystic fibrosis. Ir Med J 2009; 102: 29.

100 Rondeau S, Couderc L, Dominique S, et al. High frequency of voriconazole-related phototoxicity in cystic fibrosis patients. Eur Respir J 2012; 39: 782-784.

101 Epaulard O, Leccia MT, Blanche S, et al. Phototoxicity and photocarcinogenesis associated with voriconazole. Med Mal Infect 2011; 41: 639-645. 
102 Laoudi Y, Paolini JB, Grimfed A, et al. Nebulised corticosteroid and amphotericin B: an alternative treatment for ABPA? Eur Respir J 2008; 31: 908-909.

103 Godet C, Meurice JC, Roblot F, et al. Efficacy of nebulised liposomal amphotericin B in the attack and maintenance treatment of ABPA. Eur Respir J 2012; 39: 1261-1263.

104 Smyth A, Walters S. Prophylactic antibiotics for cystic fibrosis. Cochrane Database Syst Rev 2003; 3: CD001912.

105 Tramper-Stranders GA, Wolfs TF, van Haren Noman S, et al. Controlled trial of cycled antibiotic prophylaxis to prevent initial Pseudomonas aeruginosa infection in children with cystic fibrosis. Thorax 2010; 65: 915-920.

106 Langton Hewer SC, Smyth AR. Antibiotic strategies for eradicating Pseudomonas aeruginosa in people with cystic fibrosis. Cochrane Database Syst Rev 2009; 4: CD004197.

107 Treggiari MM, Retsch-Bogart G, Mayer-Hamblett N, et al. Comparative efficacy and safety of 4 randomized regimens to treat early Pseudomonas aeruginosa infection in children with cystic fibrosis. Arch Pediatr Adolesc Med 2011; 165: 847-856.

108 Mayer-Hamblett N, Kronmal RA, Gibson RL, et al. Initial Pseudomonas aeruginosa treatment failure is associated with exacerbations in cystic fibrosis. Pediatr Pulmonol 2012; 47: 125-134.

109 Saiman L. Infection prevention and control in cystic fibrosis. Curr Opin Infect Dis 2011; 24: 390-395.

110 Dharmaraj P, Smyth RL. Vaccines for preventing influenza in people with cystic fibrosis. Cochrane Database Syst Rev 2009; 4: CD001753.

111 Sermet-Gaudelus I, Mayell SJ, Southern KW, et al. Guidelines on the early management of infants diagnosed with cystic fibrosis following newborn screening. J Cyst Fibros 2010; 9: 323-329.

112 Moss RB. Long-term benefits of inhaled tobramycin in adolescent patients with cystic fibrosis. Chest 2002; 121: 55-63.

113 Quan JM, Tiddens HA, Sy JP, et al. A two-year randomized, placebo-controlled trial of dornase alfa in young patients with cystic fibrosis with mild lung function abnormalities. J Pediatr 2001; 139: 813-820.

114 Lands LC, Stanojevic S. Oral non-steroidal anti-inflammatory drug therapy for cystic fibrosis. Cochrane Database Syst Rev 2007; 4: CD001505.

115 Southern KW, Barker PM, Solis-Moya A, et al. Macrolide antibiotics for cystic fibrosis. Cochrane Database Syst Rev 2011; 12: CD002203

116 Saiman L, Anstead M, Mayer-Hamblett N, et al. Effect of azithromycin on pulmonary function in patients with cystic fibrosis uninfected with Pseudomonas aeruginosa: a randomized controlled trial. JAMA 2010; 303: 1707-1715.

117 Rosenfeld M, Ratjen F, Brumback L, et al. Inhaled hypertonic saline in infants and children younger than 6 years with cystic fibrosis: the ISIS randomized controlled trial. JAMA 2012; 307: 2269-2277.

118 Ramsey BW, Davies J, McElvaney NG, et al. A CFTR potentiator in patients with cystic fibrosis and the G551D mutation. N Engl J Med 2011; 365: 1663-1672.

119 Schnabel D, Grasemann C, Staab D, et al. A multicenter, randomized, double-blind, placebo-controlled trial to evaluate the metabolic and respiratory effects of growth hormone in children with cystic fibrosis. Pediatrics 2007; 119: e1230-e1238.

120 Hurley MN, Forrester DL, Smyth AR. Antibiotic adjuvant therapy for pulmonary infection in cystic fibrosis. Cochrane Database Syst Rev 2010; 10: CD008037.

121 Flume PA, O'Sullivan BP, Robinson KA, et al. Cystic fibrosis pulmonary guidelines: chronic medications for maintenance of lung health. Am J Respir Crit Care Med 2007; 176: 957-969.

122 Bell SC, Robinson PJ. Exacerbations in cystic fibrosis: 2. prevention. Thorax 2007; 62: 723-732.

123 Moskowitz SM, Silva SJ, Mayer-Hamblett N, et al. Shifting patterns of inhaled antibiotic use in cystic fibrosis. Pediatr Pulmonol 2008; 43: 874-881. 